\title{
Nd:YAG LASER CLEARANCE OF THE ANTERIOR SURFACE OF POSTERIOR CHAMBER INTRAOCULAR LENSES
}

\author{
S. J. TALKS \\ Northampton
}

\begin{abstract}
SUMMARY
Purpose: To demonstrate the use of Nd:YAG laser in clearing the anterior surface of posterior chamber intraocular lenses.

Method: Six cases are presented with the following conditions: haemorrhage, inflammatory deposits, a fibrinous papillary membrane, capsulorhexis shrinkage. Results: Nd:YAG laser was successful in managing each of these cases.

Conclusion: With careful use Nd:YAG laser clearance of the anterior surface of a posterior chamber intraocular lens can be carried out successfully without damaging the lens.

Following cataract surgery the anterior surface of posterior chamber intraocular lenses (pcIOL) can sometimes become obscured. ${ }^{1}$ This may be due to haemorrhage, inflammatory deposits, the formation of a fibrinous pupillary membrane, or the shrinkage of a small anterior capsular opening, especially following capsulorhexis.

Six cases are illustrated giving examples of these complications which failed to settle despite the use of frequent topical medication. Each of these was successfully managed with a Nd:YAG laser.
\end{abstract}

\section{METHOD}

A Lasag Nd:YAG laser was used in conjunction with a Meridian CGP1 Pupillary lens. In all cases the laser power was started at $1.5 \mathrm{~mJ}$ and increased until the appropriate response occurred. All cases were treated after lasering with acetazolamide (Diamox SR) $250 \mathrm{mg}$ b.d. for 3 days. The intraocular pressure was checked $2 \mathrm{~h}$ after treatment and after 5 days. None had a pressure rise above $22 \mathrm{mmHg}$.

From: Northampton General Hospital, Northampton, UK.

Correspondence to: Mr S. J. Talks, Oxford Eye Hospital, Radcliffe Infirmary, Woodstock Road, Oxford OX2 6HE, UK.

\section{CASE REPORTS \\ Case 1. Post-operative Haemorrhage}

A 73-year-old Caucasian insulin-dependent diabetic man, on aspirin, who had previously had a right trabeculectomy, had a right extracapsular cataract extraction $(E C C E)+$ pcIOL. At surgery a broad iridectomy was performed through the original peripheral iridectomy to enable adequate pupil dilation. This was sutured with 10.0 Prolene. No haemorrhage was noted during surgery but the next day a large blood clot covered the pupil. This did not clear with the use of prednisolone acetate $1 \%$ (Predforte) and mydriatics. The patient did not wish further surgery.

After 3 months the visual acuity was still hand movements and so Nd:YAG laser was used. The laser was applied to the organised clot at the edge of the pupil (171 pulses, at 2-3 mJ, Q switched). Most of the clot cleared leaving a fibrinous membrane. A week later the laser was used to remove this, revealing blood behind the pcIOL in the capsular bag. The posterior capsule was then punctured with the laser and the clot dispersed, allowing a view of the posterior pole (306 pulses at $2.4 \mathrm{~mJ}$ average, $\mathrm{Q}$ switched). The lens sustained a few minor nicks in the periphery but was otherwise unscathed. Unfortunately the patient's vision remained poor at $4 / 60$ due to ischaemic diabetic maculopathy (Fig. 1).

\section{Case 2. Inflammatory Deposits, Direct Treatment}

A 70-year-old Caucasian man had a left ECCE + pcIOL. Twenty-five years prior to this he had suffered a blunt injury to the eye causing an iridodialysis. This was used to perform a broad iridectomy at the time of ECCE. The iris was sutured with 10.0 Prolene. At 3 months the visual acuity was $6 / 9$ on refraction but by 6 months it had dropped to $6 /$ 24. This was due to posterior capsule thickening and inflammatory deposits on the anterior surface of the 


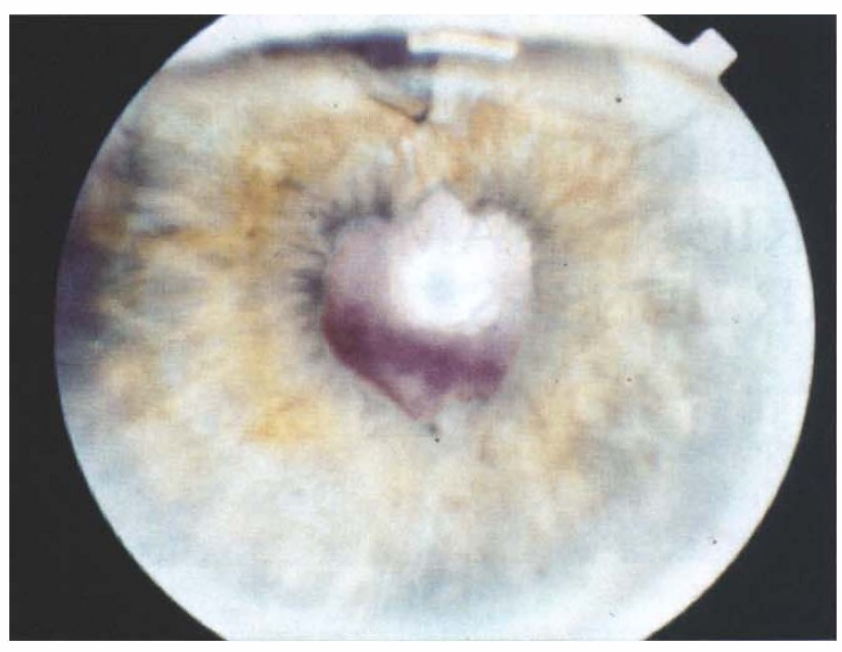

(a)

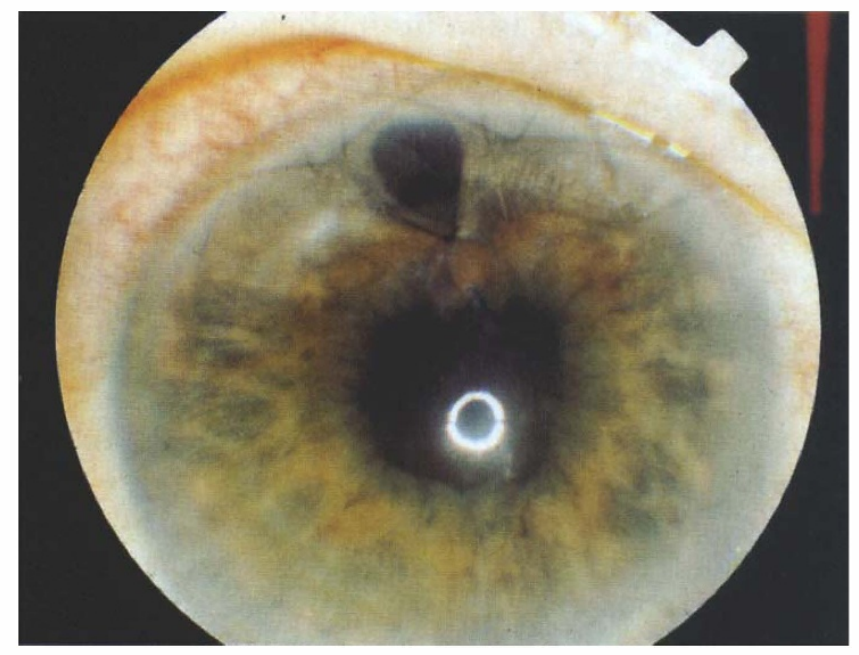

(c)

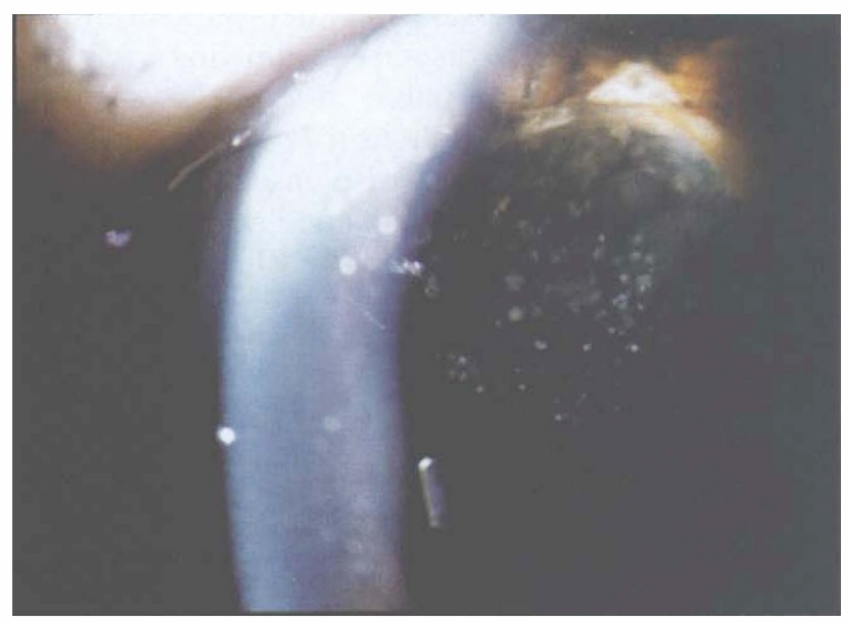

(a)

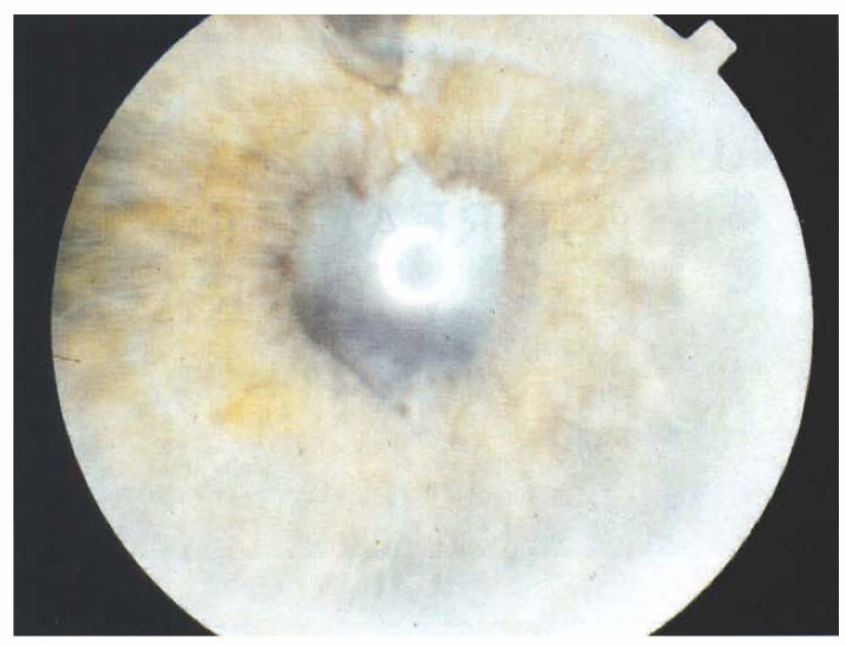

(b)

Fig. 1. (a) Blood clot covering the pupil 3 months after surgery. (b) After first laser treatment the blood clot has been dispersed, revealing a fibrinous membrane across the posterior chamber intraocular lens (pcIOL). (c) After second laser treatment the membrane has been removed and the blood clot behind the lens dispersed, giving a clear red reflex.

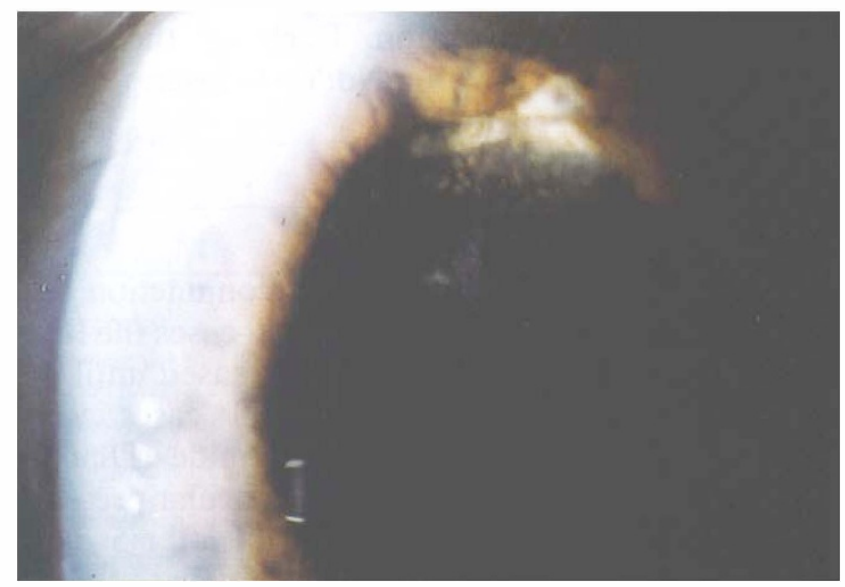

(b)

Fig. 2. Case 2. (a) Inflammatory deposits on a pcIOL. (b) pcIOL cleared after direct laser treatment. 


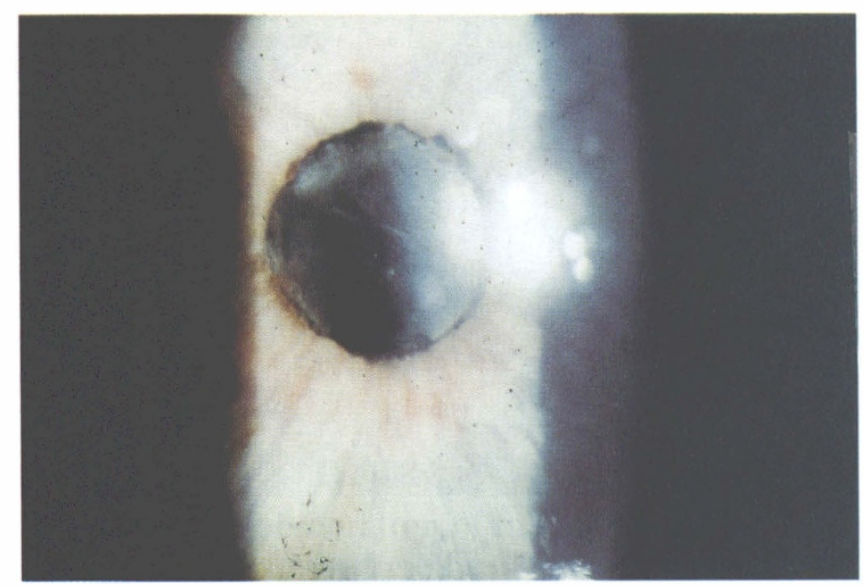

(a)

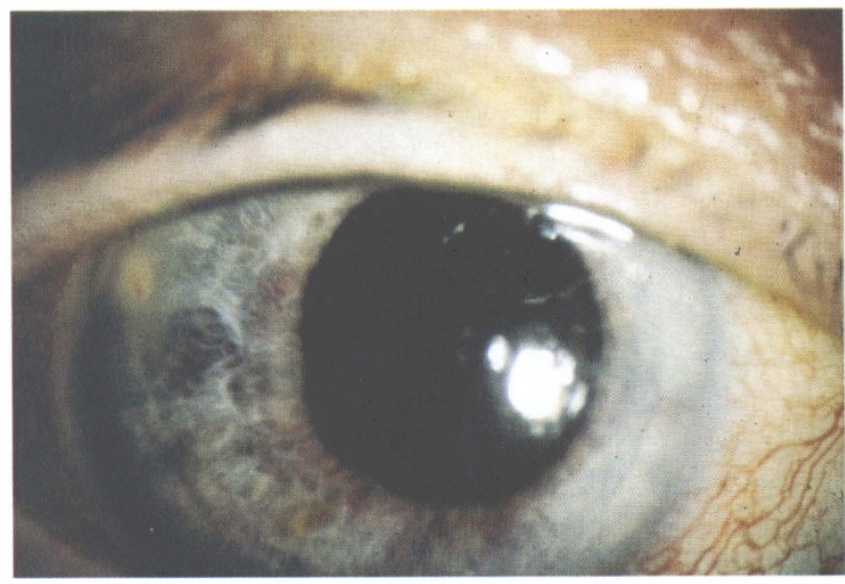

(b)

Fig. 3. Case 4. (a) Fibrinous pupillary membrane. (b) Immediately after laser treatment.


(a)

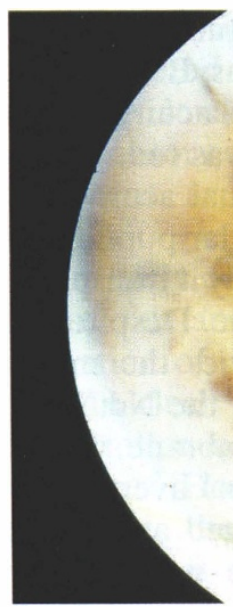

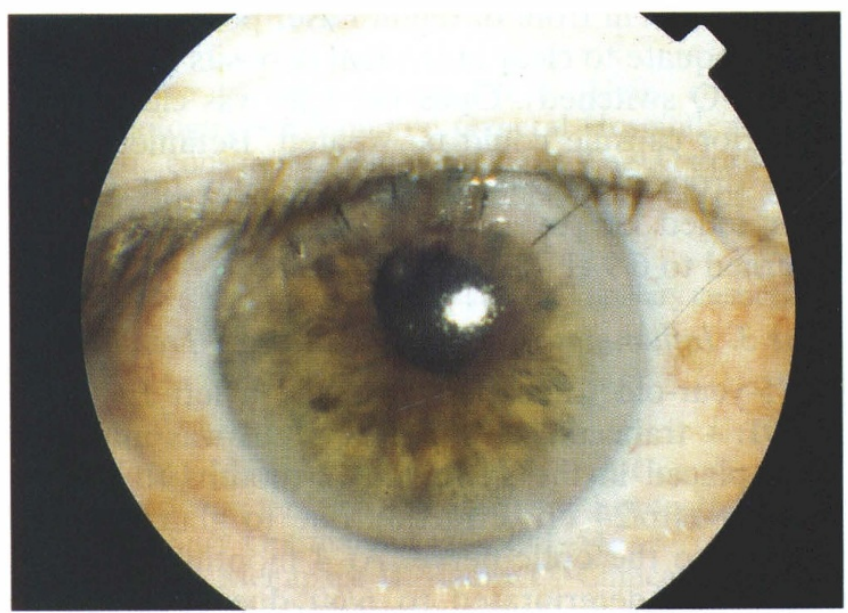

(b)

Fig. 4. Case 5. (a) Fixed miosed pupil held by a fibrinous pupillary membrane. (b) Immediately after laser treatment the membrane has been cleared and the pupil is starting to dilate. There is a small iris haemorrhage. (c) A week later after further dilation and topical steroids there is a clear red reflex. 


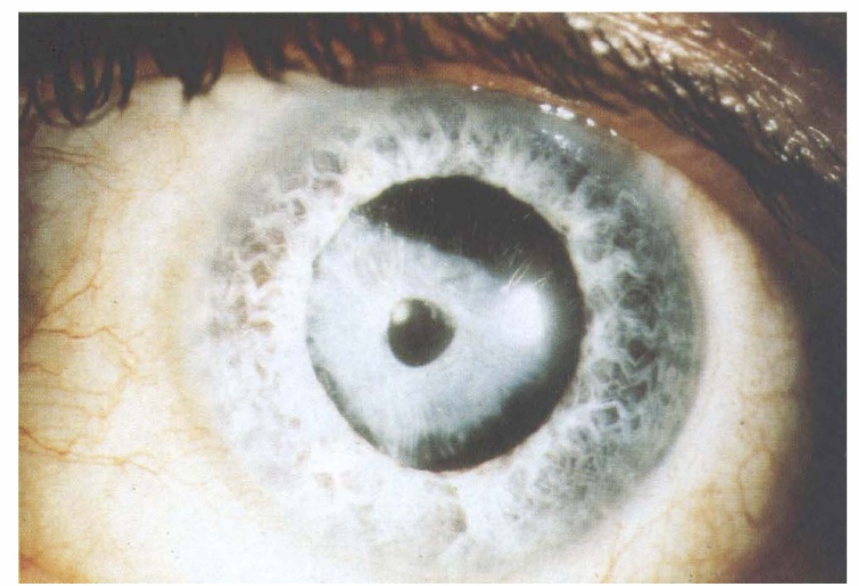

(a)

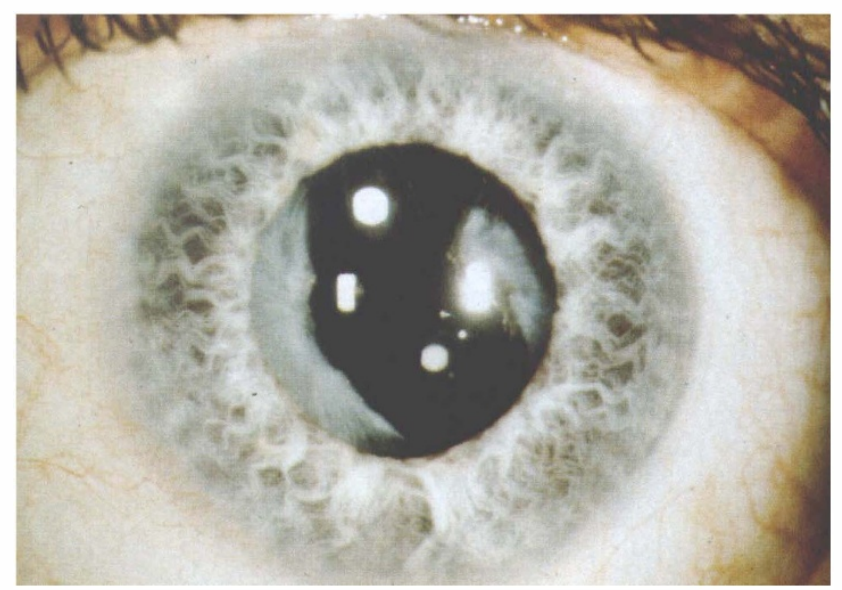

(b)

Fig. 5. Case 6. (a) Capsulorhexis shrinkage. (b) After tangential laser cuts.

pcIOL. Despite Predforte 6 times a day for 2 weeks the deposits did not clear significantly. The Nd:YAG laser was used, aiming directly at the deposits but focusing just in front of them. Laser power of $1.5 \mathrm{~mJ}$ was adequate to clear individual deposits $(1.5 \mathrm{~mJ}, 45$ pulses, Q switched). Once the lens was cleared the posterior capsule could be treated. Betamethasone $0.1 \%$ drops were used four times a day for 1 week then tailed off over 3 weeks. The visual acuity returned to $6 / 9$ (Fig. 2).

\section{Case 3. Inflammatory Deposits, Indirect Treatment}

A 75-year-old Caucasian man had a left ECCE + pcIOL + trabeculectomy. The pcIOL was inadvertently placed in the sulcus. At 2 months the visual acuity was $6 / 24$ on refraction due to glaucomatous damage to the optic nerve. At 4 months the visual acuity had deteriorated to $6 / 60$ due to posterior capsule thickening; also numerous inflammatory deposits were noted on the anterior surface of the pcIOL, which only partly cleared with topical steroid therapy. The inferior part of the posterior capsule was visible and so Nd:YAG laser treatment to the posterior capsule was performed (29 pulses at $2 \mathrm{~mJ}$, Q switched). The shock wave from the Nd:YAG laser caused the pcIOL to vibrate, dislodging the inflammatory deposits. After laser treatment topical steroids were used, at decreasing frequency, for 6 weeks and the deposits did not return. The visual acuity stabilised at $6 / 24$.

\section{Case 4. Pupillary Membrane}

An 80-year-old Caucasian woman, who had been on pilocarpine $2 \%$ q.d.s. for 15 years, had a left ECCE + pcIOL. The post-operative medication prescribed was betamethasone $0.1 \%$ and neomycin $0.5 \%$ (Betnesol N) four times a day. At 2 weeks the visual acuity was $6 / 18$ with pin hole and some fibrin was noted in the anterior chamber. The patient was advised to use Predforte 6 times a day. Unfortunately she did not return to the outpatient department for a further 2 months and had run out of drops. The visual acuity was counting fingers due to a pupillary membrane. This did not clear with hourly Predforte and mydriatics. One month later Nd:YAG laser treatment was performed. The laser was aimed at the edge of the membrane, at the pupillary margin (43 pulses of $2.2 \mathrm{~mJ}$, Q switched). This freed the pupil allowing it to dilate, leaving some fragments of membrane on the lens. With continued topical steroid treatment this cleared over 2 weeks. The final visual acuity on refraction was $6 / 12$ and the lens was unscathed (Fig. 3).

\section{Case 5. Pupillary Membrane with Very Miosed Pupil} An 85-year-old Caucasian man had a combined right $\mathrm{ECCE}+$ pcIOL + trabeculectomy. He had been on long-term pilocarpine $2 \%$ q.d.s. and timoptol $0.5 \%$ b.d. The post-operative treatment was Betnesol $\mathrm{N}$ four times a day. At 2 weeks the visual acuity was $6 /$ 12 on refraction and the Betnesol $\mathbf{N}$ was reduced to twice a day. One month later the visual acuity was hand movements due to a small irregular pupil fixed by a pupillary membrane. Unfortunately it transpired the patient had restarted his pilocarpine. Despite the use of hourly Predforte and mydriatics the membrane remained firm. Two weeks later the Nd:YAG laser was aimed at the edge of the membrane, where it attached to the iris $(55$ pulses at $2 \mathrm{~mJ}$ average, $\mathrm{Q}$ switched). The membrane was dislodged and disintegrated and the pupil dilated. There was a small amount of bleeding from the iris but this soon settled. After laser treatment Predforte was prescribed six times a day for 1 week, which was then tailed off over 1 month. At this time the visual acuity on refraction was $6 / 9$ (Fig. 4). 


\section{Case 6. Capsulorhexis Shrinkage}

A 50-year-old Caucasian man had a left phacoemulsification and insertion of a foldable silicone pcIOL. At 4 months he complained of monocular diplopia and glare. His visual acuity was $6 / 9$ on refraction. The anterior capsule was found to have opacified and the capsulorhexis to have contracted over most of the anterior surface of the pcIOL. The Nd:YAG laser was used to cut two tangential tears in the anterior capsule which caused the capsule to retract and clear the pcIOL (53 pulses at $2.6 \mathrm{~mJ}$, Q switched) (Fig. 5).

\section{DISCUSSION}

Post-operative obscuration of the anterior surface of a pcIOL can be treated medically, surgically or with a Nd:YAG laser.

Haemorrhage obscuring the pupil may settle in time or can be removed by surgical washout. This can, however, be dificult as the blood will be clotted and may well be in front of and behind the pcIOL. ${ }^{2}$ The injection of tissue plasminogen activator (tPA) into the anterior chamber prior to washout has been advocated as this dissolves the clot, greatly facilitating its removal. ${ }^{3} \mathrm{Nd}$ :YAG laser can successfully clear such haemorrhages but a lot of power may be required, as in this case. ${ }^{2}$ Despite this the intraocular pressure did not rise significantly and the lens remained relatively unscathed.

Inflammatory deposits on a pcIOL surface will usually clear with the use of topical steroid. Some cellular material is to be expected on the surface of pcIOLs, but not, it is hoped, of a macroscopic nature. ${ }^{4}$ In the cases presented the inflammatory deposits only partially cleared with topical treatment, but in addition posterior capsule opacification had developed. The weak adherence of these deposits was demonstrated as they fell off after Nd:YAG laser to the posterior capsule caused the pcIOL to vibrate. This lens movement clearly demonstrated that sulcus-fixated lenses are not as stable as lenses in the capsular bag. If necessary inflammatory deposits can also be removed by direct treatment, as illustrated, without endangering the lens.

The early detection of fibrin and the adequate use of steroids and mydriatics will usually prevent the formation of a fibrinous membrane. tPA has been used to clear post-operative fibrin formation, especially following vitrectomy, but also after cataract surgery. ${ }^{3,5}$ However, to be effective it needs to be given in the early post-operative period and hyphaema is a risk factor. ${ }^{6}$ In some cases once a membrane is established medical treatment is not effective. Nd:YAG laser is then probably the best method of removing the membrane, as with careful aim at the membrane/iris junction the membrane will be found to split free of the lens. Gandham et al. ${ }^{7}$ reported 7 cases in which this technique was successful. In their cases combined cataract and glaucoma surgery was the main risk factor for pupillary membrane formation. The chronic use of miotics has also been associated. ${ }^{8}$ When capsulorhexis is used during cataract surgery a fibrinous membrane can develop across the capsulorhexis, obscuring the lens, without actually adhering to the pupil. If this does not settle medically Nd:YAG laser may be needed.

Post-operatively the capsule may become opaque and contract. ${ }^{9}$ If a capsulorhexis is used this can lead to shrinkage of the opening and visual disturbance as described. ${ }^{10,11}$ In severe cases the anterior capsule can shrink completely over the lens. ${ }^{12}$ Remaining lens epithelial cells may be an especially important factor in causing this problem. ${ }^{9}$ Splitting the capsulorhexis with the Nd:YAG laser is effective. ${ }^{10-12}$

$\mathrm{Nd}$ :YAG laser can cause complications including IOL damage, raised intraocular pressure and iris bleeding. ${ }^{13}$ However, with careful use these need not be a problem and in many cases the patient can be spared further surgery.

I would like to acknowledge $\mathrm{Mr} \mathrm{P}$. Hein, consultant ophthalmologist Northampton General Hospital, and $\mathrm{Mr}$ P. Rosen, consultant ophthalmologist The Oxford Eye Hospital, for allowing me to include details of their patients.

Key words: Nd:YAG laser, Intraocular lens, Pupillary membrane.

\section{REFERENCES}

1. Apple DJ, Mamalis N, Loftfield K, et al. Complications of intraocular lenses: a historical and histopathological review. Surv Ophthalmol 1984;29:1-54.

2. Hagan JC, Menapace R, Radax U. Clinical syndrome of endocapsular hematoma: presentation of a collected series and review of the literature. J Cataract Refract Surg 1996;22:379-84.

3. Jaffe GJ, Abrams GW, Williams GA, Han DP. Tissue plasminogen activator for postvitrectomy fibrin formation. Ophthalmology 1990;97:184-9.

4. Amon A, Menapace R. In vivo documentation of cellular reactions on lens surfaces for assessing the biocompatibility of different intraocular implants. Eye 1994;8:649-56.

5. Lesser GR, Osher RH, Whipple D, et al. Treatment of anterior chamber fibrin following cataract surgery with tissue plasminogen activator. J Cataract Refract Surg 1993;19:301-5.

6. Folk JC, Hershey JM, Rivers MB. Lack of effectiveness of tissue plasminogen activator 20 or more days after vitrectomy. Arch Ophthalmol 1991;109:614.

7. Gandham SB, Brown RH, Katz JL, Lynch MG. Neodymium:YAG membranectomy for pupillary membranes on posterior chamber intraocular lenses. Ophthalmology 1995;102:1846-52.

8. Chen HS, Steinmann WC, Spaeth GL. The effect of chronic miotic therapy on the results of posterior chamber intraocular lens implantation and trabeculectomy in patients with glaucoma. Ophthalmic Surg 989;20:784-9. 
9. Choun-Ki J, Ah-Jeong S, Jae-Ho K. Capsular opening contraction after continuous curvilinear capsulorhexis and intraocular lens implantation. J Cataract Refract Surg 1996;22:585-90.

10. Young DA, Orlin SE. Capsulorhexis contracture in phacoemulsification surgery. Ophthalmic Surg 1994;25: 477-8.

11. Nishi $\mathrm{O}$, Nishi K. Intraocular lens encapsulation by shrinkage of the capsulorhexis opening. J Cataract Refract Surg 1993;19:544-5.

12. Toldos JJM, Roig AA, Benabent EC. Total anterior capsule closure after silicone intraocular lens implantation. J Cataract Refract Surg 1996;22:269-71.

13. Aron-Rosa DS, Aron JJ, Cohn HC. Use of a pulsed picosecond Nd:YAG laser in 6664 cases. Am Intraocular Implant Soc J 1984;10:35-40. 